\title{
On the Internet of Things, smart cities and the WHO Healthy Cities
}

Maged N Kamel Boulos ${ }^{1 *}$ and Najeeb M Al-Shorbaji ${ }^{2}$

\begin{abstract}
This article gives a brief overview of the Internet of Things (loT) for cities, offering examples of loT-powered 21st century smart cities, including the experience of the Spanish city of Barcelona in implementing its own loT-driven services to improve the quality of life of its people through measures that promote an eco-friendly, sustainable environment. The potential benefits as well as the challenges associated with loT for cities are discussed. Much of the 'big data' that are continuously generated by loT sensors, devices, systems and services are geo-tagged or geo-located. The importance of having robust, intelligent geospatial analytics systems in place to process and make sense of such data in real time cannot therefore be overestimated. The authors argue that loT-powered smart cities stand better chances of becoming healthier cities. The World Health Organization (WHO) Healthy Cities Network and associated national networks have hundreds of member cities around the world that could benefit from, and harness the power of, loT to improve the health and well-being of their local populations.
\end{abstract}

Keywords: Urban health, WHO Healthy Cities, Smart cities, Internet of Things, Big data, Smart location, Sensors, Citizen sensing, Participatory governance, Environmental sustainability

\section{Background: the 'Internet of Things' (and people)} In a major review article published in December 2011, Kamel Boulos et al. [1] describe and discuss in great detail an 'Internet-connected web of citizens (people) and electronic sensors/devices (things)' that can serve many functions related to public and environmental health surveillance and crisis management applications. Subsequent articles and conference slides by Kamel Boulos [2-4] provide additional human health-related examples of applications harnessing the power of Internet-connected people and things, e.g., community-led air quality monitoring around the globe using the 'Air Quality Egg' sensor system [5] and crowdsourced noise pollution monitoring by citizens using a special app running on their smartphones [6,7].

Ashton [8] was probably the first person to coin the phrase-term 'Internet of Things' (IoT) back in 1999 to describe this vision (now reality) of Internet-connected sensors, devices and citizens. Ashton's phrase-term later made the title of a Scientific American article by Gershenfeld et al. [9] published in October 2004, and

\footnotetext{
* Correspondence: mnkboulos@ieee.org

'Plymouth University, Devon, United Kingdom

Full list of author information is available at the end of the article
}

more recently the title of a short column by Skiba [10] that appeared in the January/February 2013 issue of Nursing Education Perspectives, among very many other publications today on the subject of IoT.

\section{loT-powered smart cities of the 21st century: promises and challenges}

As the Internet and other relevant technologies continued to develop and mature over the first decade of the 21st century, a number of solutions from market giants such as Cisco [11,12], IBM [13,14] and others emerged that made IoT a feasible option for a good number of modern cities and metropolises today. Indeed, IoT is often perceived as a major enabler for the 'smart cities' of the present and future [15]. IoT-powered smart cities aim at improving the quality of life of their populations in a variety of ways, including through measures that promote eco-friendly, sustainable environments and the delivery of 'connected health/care' services to citizens at home and on the move.

Fitbit [16] and other Internet-connected, gamified (i.e., with game-like features) fitness gadgets and apps [17] are good examples of this 'connected health/care' 
vision realised through IoT technology. Modern telehealthcare services also belong to the same 'connected health/ care' paradigm, as pioneered, for example, in the CAALYX EU-funded research project series (Complete Ambient Assisted Living Experiment - [18]) and in other related research projects and commercial solutions featuring wearable wireless health sensors. The latter can take the form of 'smart garments/vests' with specialised conductive areas functioning, for example, as an axillary body temperature sensor or heart rate/ECG (electrocardiogram) electrodes that wirelessly relay their measurements to remote servers over the Internet [19]. However, the deployment of such telehealthcare solutions on a large city or country-wide scale is still facing many challenges as of 2014 [20].

IoT-driven services generate big amounts of real-time data (not all of which are trustworthy and reliable), and often have associated privacy and security implications $[1,21]$. Besides the need to properly justify and plan the large investments in IoT solutions (by carrying out extensive impact, risk and cost-benefit assessments, which are not trivial tasks), other challenges facing smart cities and smart-cities-to-be include how to make sense and best use of such 'big data', while preserving citizens' privacy and data security. Cities can only be really 'smart' if they have in place the necessary intelligent, robust and reliable functions to integrate and synthesise these big data and filter out any unwanted 'noise' for the purpose of improving city efficiency, equity, sustainability and quality of life [21].

The topic of 'smart cities' is among the hottest emerging research and business themes of the 21st century. Acknowledging its importance, University College London (UCL) launched its MSc and MRes in Smart Cities in 2014 [22]. In a keynote presentation at the 2014 Consumer Electronics Show in Las Vegas, Cisco CEO John Chambers estimated the opportunity for IoT in the private and public sectors combined to be around US \$19 trillion over the next decade $[23,24]$. He described how IoT in hyperconnected cities could, for example, transform the retail industry through smart shopping carts and virtual concierges, reduce city energy costs for streetlights, revolutionise city waste management through connected garbage bins, and change the way cities handle parking through a real-time parking finder communicating with connected parking spots [23].

\section{Examples of smart cities and of loT-driven smart city applications and services}

Examples of hyperconnected smart cities are given in [25] and include Masdar in United Arab Emirates, Songdo in South Korea, over a dozen of cities in China, and many more cities in Europe (see also [26] and the SmartSantander project [27]) and the rest of the world. In the UK, Bristol City Council is developing a smart city service within the SPHERE project (Sensor Platform for HEalthcare in a Residential Environment, 2013-2018) to monitor the health and well-being of people living at home $[28,29]$. Bristol also has a more extensive smart city agenda that goes beyond home telehealthcare services [30]. Moving north, Glasgow (Scotland) is similarly running an ambitious $£ 24$ million (GBP) programme to demonstrate how technology can make life in the city smarter, safer and more sustainable [31].

Love Clean Streets [32] is a UK app that enables Internetconnected citizens to use their mobile phones' built-in GPS (Global Positioning System) and camera to document and directly report to their local authorities any environmental or neighbourhood issues or crimes they might come across while travelling in the city. Users can later visit the Love Clean Streets Web site to review the progress of their reports. City councils across the UK are responding very well and promptly to citizens' reports filed via the Love Clean Streets mobile app, which is a good example of the active engagement and participation of members of the general public in the day-to-day running and maintenance of their own cities.

\section{Barcelona (Spain) and the 'Internet of Everything'}

Cisco calls its own "version" of IoT the 'Internet of Everything' [12,33,34]. Barcelona, the capital city of the autonomous community of Catalonia in Spain [35], teamed up with Cisco to deploy city-wide IoT systems and services to better serve its citizens and visitors [36-39]. The 'Internet of Everything' acts as the backbone around which technological initiatives are being undertaken in Barcelona, rather than doing projects in silo [23]. A $500 \mathrm{Km}$ long underground fibre network is being installed progressively as the city carries out routine maintenance to its roads and other underground services, which helps reduce installation costs significantly [39].

Barcelona's smart bus stops are connected to the city's fibre network. They display real time bus timetables, tourist information and digital advertising, offer USB (Universal Serial Bus) charging sockets for mobile devices such as smartphones and tablets, and act as free WiFi hotspots, allowing people to connect to the Internet using their mobile devices while waiting for a bus [36,39]. The city's smart parking spots are also connected to Barcelona's WiFi network. They detect the presence of cars through a combination of light and metal detectors, but do not currently work with motorcycles. Online searching and payment for the smart parking spots is possible using dedicated smartphone apps [34,36,39].

A city-wide network of sensors provides real-time valuable information on the flow of citizens, noise and other forms of environmental pollution, as well as traffic and weather conditions. This enables the local authorities to 
streamline city operations including better environmental management, reduce costs, and improve economic, social and environmental sustainability. Barcelona's highlyenergy-efficient streetlights are connected to the city's underground fibre network. They have been fitted with multiple features including CCTV (closed-circuit television), air quality monitoring sensors and WiFi, and are capable of dynamically managing the level of lighting depending on surrounding conditions to save energy (e.g., dim lights when no motion or pedestrians are detected in the street) [36,39].

Barcelona's wirelessly-connected garbage bins are fitted with sensors that monitor trash levels (future versions of the sensors are expected to also detect the presence of hazardous materials that might be dumped in the bin). The data reach the city council's team in charge, enabling the team to plan the optimal routes for garbage collection, update garbage truck drivers in real time regarding which routes to take, and in this way optimise productivity and reduce waste management service costs [36,39].

According to Antoni Vives, Barcelona's Deputy Mayor for Urban Habitat, the main rationale behind his city's embracement of IoT is to improve the quality of life of people. Thanks to IoT, the city was able to make big savings in areas such as smart water (savings of $€ 42.5$ million [US \$58 million] a year) and lighting and parking management (increased revenues of parking fees by $33 \%$ or $€ 36.5$ million [US $\$ 50$ million]), besides creating 47,000 new jobs related to the smart city developments in Barcelona [23]. In a video interview posted online in November 2013, Antoni Vives proceeds to describe his ultimate vision of a smarter Barcelona in ten years' time as "a city of culture, creativity, knowledge but mainly fairness and well-being; a place where people live near where they work; a city self-sufficient in energy; a zero emission city and a city hyperconnected to the world" [38].

\section{The WHO Healthy Cities programme}

Smart cities include important ingredients for a healthier environment and for improved quality of life and wellbeing of city dwellers. This echoes in a strong way the mission of the WHO (World Health Organization) Healthy Cities project, which started in 1987 (Phase I) and is currently, as of 2014, in Phase VI [40]. The WHO defines a 'healthy city' as one that is continually creating and improving those physical and social environments and expanding those community resources which enable people to mutually support each other in performing all the functions of life and in developing to their maximum potential [41].

The WHO Healthy Cities programme [42] is a longterm international development initiative that aims to place health high on the agendas of decision makers, and to promote comprehensive local strategies for health protection and sustainable development. Basic features include community participation and empowerment, intersectoral partnerships and participant equity.

As part of this global programme, about 90 cities are members of the WHO European Healthy Cities Network, and 30 national Healthy Cities networks across the WHO European Region have more than 1400 cities and towns as members [40]. The primary goal of the WHO European Healthy Cities Network is to put health high on the social, economic and political priorities of city governments. Health should be the business of all sectors, and local governments are in a unique leadership position, with power to protect and promote their citizens' health and well-being.

The Healthy Cities movement promotes comprehensive and systematic policy and planning for health, emphasising and addressing the need to address inequality in health and urban poverty; the needs of vulnerable groups; participatory governance; and the social, economic and environmental determinants of health. A multi-sectoral approach offers good basis for policy and action, as health is considered an outcome of multiple inputs form different sectors. These include the economic, education, cultural, environmental, social, industrial and public services sectors.

With the emergence of the 'information society', the smart cities concept started to become a reality, as more cities of the world in general and in Europe in particular realised that to become healthier they have to go digital. 'Digital economy', 'information economy' and 'knowledge society' all began to be recognised as integral concepts and components of city planning and sustainable development. Smart cities share common characteristics as they move from focusing their investment on traditional, physical infrastructure to more emphasis on digital infrastructure, including information and communications technology (ICT) to support the knowledge economy.

Moving the society to become more connected, networked and data driven is the cornerstone in health cities. City mayors, policy makers and planners, in their effort to create smart and healthy cities, tend to depend more on information infrastructure to keep their citizens more informed, engaged and empowered. The same digital infrastructure enables citizens to actively contribute to, and become part of the drive for sustainable development, as well as to self-manage their own health and well-being to live longer and healthier.

Digital health using smart cards is just one example of how citizens can be empowered to take care of their own health and play an active role in their own healthcare schemes. They are empowered to take decisions through better access to quality health information. Digital health has allowed for patients to stay less in 
hospitals and more at home, thanks to monitoring sensors and devices, transmitting alerts and other relevant data over mobile networks and the Internet.

\section{Discussion and conclusions Innovation for sustainability}

In a 2011 TED Talk entitled 'The surprising math of cities and corporations', Geoffrey West, a British theoretical physicist and former President and Distinguished Professor of the Santa Fe Institute in the United States, puts forward 'innovation' as the key to avoiding collapse and promoting sustainability of large cities and their infrastructures (see [43] at time position 15:03). IoT for cities can be regarded as a (or the) major innovation in this respect.

According to Roberto Saracco, Chair of IEEE's (Institute of Electrical and Electronics Engineers) Future Directions Committee and EIT ICT Labs Italian Node Director, "the city of the future will be self-aware, much like a being" [44]. It will be able to dynamically reconfigure itself, based on what is currently happening and what can be predicted to occur in the future. Saracco describes two versions of cities: one made of atoms (humans, vehicles, buildings, etc.) and a mirror version made of bits. The two versions are connected to one another via sensors [44].

\section{The need to engage and raise the awareness of all stakeholders}

However, for any city to realise the full potential of IoT for cities, it will have to involve and engage its stakeholders from a very early stage (city officials at all levels, as well as citizens), and to secure their support by raising their awareness and educating them about smart city technologies, the associated benefits, and the likely challenges that will need to be overcome (such as privacy issues [45]). The IEEE, the world's largest not-for-profit professional association for the advancement of technology, is already helping and playing an important role in this respect through its 'IEEE Urbanization Challenge' activities [46].

\section{The risks exist at the interfaces: the role of standards}

IoT-powered smart cities rely on a growing number of sub-technologies and subsystems (devices, appliances, buildings, vehicles, component services, etc.) that need to be seamlessly interconnected and interfaced with one another in real time. (See, for example, the emerging EU 'connected cars' vision and standards, which have the potential of reducing traffic bottlenecks and road traffic accidents, in addition to improving ambulance response times $[47,48])$.

ICT projects prone to failure are commonly complex systems made up of a large number of different subsystems that are all supposed to tie well and work together.
While this seems to offer the opportunity for the most (integration) benefits, it seems to create the most (interfacing) problems. When one is trying to integrate lots of different subsystems, one is going to face and have to deal with interface risks [49]. Standards are key to mitigating the latter.

The World Health Assembly resolution on standardisation and interoperability (May 2013) makes it clear in its preamble that "the secure, effective and timely transmission of personal data or population data across information systems requires adherence to standards on health data and related technology" [50].

Besides IEEE's efforts and standards in this domain (such as IEEE 802.15.4 standard for low-rate wireless personal area networks [LR-WPANs]), as well as those by ISO-International Organization for Standardization/ IEC-the International Electrotechnical Commission (such as ISO/IEC 18092 standard for Near Field Communication [NFC], one of IoT's important technologies [51]), the Open Geospatial Consortium (OGC) is sponsoring many complementary activities in relation to the geospatial aspects of, and standards for, IoT [1,52].

\section{Pairing big and small data}

Much of the 'big data' generated by IoT sensors, devices, systems and services are geo-tagged or geo-located (location gives important context [where], as well as being an essential piece of information to know when responding to events/deploying appropriate actions). The importance of having robust, intelligent geospatial analytics systems in place to process and make sense of such data in real time cannot be overestimated [53,54]. This applies to all aspects of city life, including the health of its citizens. Indeed, health is geospatial, and if we can see trends spatially, we can monitor (and improve) population and individuals' health [55]. But 'big data' methods can only be truly useful if they are paired with traditional forms of information collection, or what some researchers call 'small data' [56,57].

\section{IoT for healthier cities}

The Internet of Things is rapidly gaining a central place as key enabler of the smarter cities of today and the future. Such cities also stand better chances of becoming healthier cities. The WHO and associated national Healthy Cities networks have hundreds of member cities around the world that could benefit from, and harness the power of, IoT to improve the health and well-being of their local populations. As we were wrapping up this article in March 2014, the UK government announced it will spend an extra $£ 45$ million (GBP) on developing IoT technologies [58], which is refreshing to hear and shows the importance of these technologies for modern cities and economies. 


\section{Competing interests}

The authors declare that they have no competing interests. Any reference herein to any specific commercial apps, devices, other products, or services by trade name, trademark, manufacturer, provider, or otherwise does not necessarily constitute or imply its endorsement, recommendation or favouring by the authors or the institutions they are affiliated with. Commercial products, services and company/brand names mentioned in this paper are trademarks and/or registered trademarks of their respective owners.

\section{Authors' contributions}

MNKB conceived the manuscript's idea, researched and wrote the paper. NMA-S contributed the text for the middle section entitled 'The WHO Healthy Cities programme'. Both authors read and approved the final manuscript.

\section{Acknowledgements}

The corresponding author (MNKB) wishes to thank the very many participants from all relevant sectors at the 'Governance for health at the local level: People, citizens and assets for health, the Third Annual Business and Technical Conference of the WHO European Healthy Cities Networks and the Network of European National Healthy Cities Networks in Phase V: Initial consultation with local governments on the new health policy for the WHO European Region - Health 2020, 15-18 June 2011; Liège, Belgium', for the formative discussions that partially led to conceiving this article. The World Health Organization Regional Office for Europe (WHO EURO) reimbursed MNKB's travel costs to that event, which he attended in the capacity of 'WHO Expert Adviser' to deliver an invited speech entitled 'How social media and sociable tools (including crowdsourcing) are impacting the way we interact and make decisions on matters that relate to our health and well-being'.

\section{Author details}

${ }^{1}$ Plymouth University, Devon, United Kingdom. ${ }^{2}$ World Health Organization, Geneva, Switzerland.

\section{Received: 19 March 2014 Accepted: 24 March 2014}

Published: 27 March 2014

\section{References}

1. Kamel Boulos MN, Resch B, Crowley DN, Breslin JG, Sohn G, Burtner R, Pike WA, Jezierski E, Chuang K-YS: Crowdsourcing, citizen sensing and Sensor Web technologies for public and environmental health surveillance and crisis management: trends, OGC standards and application examples. Int J Health Geogr 2011, 10:67. http://www.ij-healthgeographics.com/ content/pdf/1476-072X-10-67.pdf.

2. Kamel Boulos MN: Seeing through the crowds: crowdmaps visualize userreported data. GeoWorld 2012, 25(6):22-25. http://tinyurl.com/geoplacecom-cache.

3. Kamel Boulos MN: Towards citizen-led health mapping. GeoConnexion: UK 2013, 11(5):54-56. http://www.geoconnexion.com/uploads/ publication_pdfs/uk-v11i5-article-towards-citizen.pdf.

4. Kamel Boulos MN: Public engagement and participation in health geography: crowdmaps (crowdsourced maps) by citizens, for citizens. In Proceedings of GEOMED 2013, the 8th international interdisciplinary conference on spatial epidemiology, spatial statistics and geomedical systems. Sheffield, UK: The Edge-University of Sheffield conference venue; 2013:16-18. http://tinyurl.com/MNKB-Geomed2013.

5. Air Quality Egg. http://airqualityegg.com/

6. Stevens $M$, D'Hondt E: Crowdsourcing of pollution data using smartphones. In Proceedings of Workshop on Ubiquitous Crowdsourcing, held at Ubicomp '10. Copenhagen, Denmark: 12th ACM International Conference on Ubiquitous Computing; 2010:26-29. http://soft.vub.ac.be/Publications/2010/vub-tr-soft-1015.pdf.

7. NoiseTube. http://noisetube.net/

8. Ashton K: That 'Internet of Things' thing: in the real world, things matter more than ideas. RFID J 2009. online. http://www.rfidjournal.com/articles/ view?4986.

9. Gershenfeld N, Krikorian R, Cohen D: The internet of things. Sci Am 2004, 291(4):76-81. http://cba.mit.edu/docs/papers/04.10.i0.pdf.
10. Skiba DJ: The Internet of Things (IoT). Nurs Educ Perspect 2013, 34(1):63-64. http://dx.doi.org/10.5480/1536-5026-34.1.63.

11. Cisco: Smart + Connected Communities. http://www.cisco.com/web/strategy/ smart_connected_communities.html.

12. Cisco: The Internet of Everything for Cities. http://www.cisco.com/web/about/ ac79/docs/ps/motm/loE-Smart-City_PoV.pdf.

13. IBM: The Internet of Things. http://www-01.ibm.com/software/info/internetof-things/.

14. IBM and Libelium Launch Internet of Things Starter Kit. http://www-03.ibm. com/press/us/en/pressrelease/42227.wss.

15. Chambers J: Are you ready for the Internet of everything? World Econ Forum Blog 2014. online. http://forumblog.org/2014/01/are-you-ready-forthe-internet-of-everything/.

16. Fitbit. http://www.fitbit.com/.

17. Kamel Boulos MN, Yang SP: Exergames for health and fitness: the roles of GPS and geosocial apps. Int J Health Geogr 2013, 12:18. doi:10.1186/1476072X-12-18.

18. Kamel Boulos MN, Rocha A, Martins A, Vicente ME, Bolz A, Feld R, Tchoudovski I, Braecklein M, Nelson J, Laighin GO, Sdogati C, Cesaroni F, Antomarini M, Jobes A, Kinirons M: CAALYX: a new generation of locationbased services in healthcare. Int J Health Geogr 2007, 6:9. doi:10.1186/ 1476-072X-6-9

19. Kamel Boulos MN: Telehealthcare for older people with comorbidity: lessons from eCAALYX and project walk-through. 2013. http://www.slideshare.net/sl. medic/mnkb-12-mar2013aalinnovateuk.

20. Kamel Boulos MN: Telehealthcare for older people: barriers to large-scale roll-outs (Round table: use of technologies to promote healthy aging and improve disability). In Proceedings of the 1st Barcelona Conference on Healthy Aging. Barcelona, Spain: University of Barcelona; 2013. http://www. slideshare.net/sl.medic/telehealthcare-for-older-people-28-barcelona2c15nov201329-v141113

21. Wachowicz M: Harnessing the smart city space of tomorrow (New Frontiers for Geomatics). GIM Int 2013, 27(10). online. http://www.gim-international.com/issues/articles/id2029-New_Frontiers_ for_Geomatics.html.

22. Introducing the MSC and MRes Smart Cities at the Bartlett Centre for Advanced Spatial Analysis. http://www.digitalurban.org/2014/02/introducing-the-mscand-mres-smart-cities-at-the-bartlett-centre-for-advanced-spatial-analysis.html.

23. Guglielmo C: CES LIVE: Cisco's chambers says internet of everything, $\$ 19$ trillion opportunity, is next big thing. Forbes 2014. Jan 7, online. http://www.forbes.com/sites/connieguglielmo/2014/01/07/ces-live-ciscoceo-chambers-to-deliver-keynote/.

24. Cisco Consulting Services: The Internet of Everything-A \$19 Trillion Opportunity. 2014. http://www.cisco.com/web/services/portfolio/consultingservices/documents/consulting-services-capturing-ioe-value-aag.pdf.

25. Smart Cities, not only new Research Papers but also exciting forecast!. 2012 http://ict4green.wordpress.com/2012/02/11/smart-cities-not-only-newresearch-papers-but-also-exiting-forecast/.

26. European Initiative on Smart Cities. http://setis.ec.europa.eu/set-planimplementation/technology-roadmaps/european-initiative-smart-cities.

27. SmartSantander. http://www.smartsantander.eu/.

28. British city promotes high-tech healthcare as a smart city service. http://smartcitiescouncil.com/article/british-city-promotes-high-techhealthcare-smart-city-service.

29. EPSRC IRC 'SPHERE' - a Sensor Platform for HEalthcare in a Residential Environment. http://gow.epsrc.ac.uk/NGBOViewGrant.aspx?GrantRef=EP/K031910/1.

30. Bristol City Council: Connect Bristol Feasibility Study. 2012. https://connect innovateuk.org/documents/3130726/6091879/Feasibility+Study+-+Bristol +City+Council.pdf/4269233f-cd8b-47da-9f0b-58a27294a684.

31. Future City | Glasgow. http://futurecity.glasgow.gov.uk/.

32. Love Clean Streets. http://www.lovecleanstreets.org/

33. Cisco: Internet of Everything. http://internetofeverything.cisco.com/.

34. Cisco: Internet of Everything: Circle Story (:60) (video, January 2014). http://www.youtube.com/watch?v=Kt5VulFqBm4

35. The website of Barcelona city - Ajuntament de Barcelona. http://www.bcn.cat/en/.

36. Cisco España: Internet of Things World Forum Barcelona 2013 (video November 2013). http://www.youtube.com/watch?v=yeof1x|H7O4.

37. Cisco: The Impact of Internet of Everything on Barcelona. (video, January 2014) http://www.youtube.com/watch?v=p34YUzCyzOA.

38. Building a smarter city: Interview with Antoni Vives Deputy Mayor of Barcelona (video, November 2013). http://www.youtube.com/watch?v=cAmn9gQhMVl. 
39. Wallbank P: A geek's tour of Barcelona. 2013. http://paulwallbank.com/2013/ 11/01/touring-barcelona-smart-city-internet-of-things/.

40. World Health Organization: The WHO Healthy Cities project. http://www.euro. who.int/en/health-topics/environment-and-health/urban-health/activities/ healthy-cities.

41. World Health Organization: Health promotion glossary. 1988. http://www. who.int/healthpromotion/about/HPR\%20Glossary\%201998.pdf.

42. World Health Organization: Types of Healthy Settings: Healthy Cities. http://www.who.int/healthy_settings/types/cities/en/.

43. Geoffrey West: The surprising math of cities and corporations (video, TED Talks, July 2011). http://www.youtube.com/watch?v=XyCY6mjWOPC.

44. IEEE Technical Community Spotlight: A Vision of a Smart, Happy, City. 2014 http://sites.ieee.org/spotlight/a-vision-of-a-smart-happy-city/.

45. Rozenfeld M: The Value of Privacy: Safeguarding your information in the age of the Internet of Everything (EEE - The Institute Online, 7 March 2014). http://theinstitute.ieee.org/technology-focus/technology-topic/the-value-ofprivacy.

46. IEEE Urbanization Challenge. http://smartcities.ieee.org/.

47. European Commission: New connected car standards put Europe into top gear (Press release, 12 February 2014). http://europa.eu/rapid/press-release_IP14-141_en.htm.

48. European Commission: Q\&A on Connected Cars (MEMO/14/105, 12 February 2014). http://europa.eu/rapid/press-release_MEMO-14-105_en.htm.

49. Big IT Projects Fail Worldwide: Multi-billion-dollar failures in the UK and California demonstrate the hubris of big software projects (IEEE Spectrum Podcast interview with software systems expert Robert N. Charette, 9 December 2009). http://spectrum.ieee.org/podcast/computing/software/big-it-projectsfail-worldwide.

50. eHealth standardization and interoperability (The Sixty-sixth World Health Assembly, WHA66.24, Agenda item 17.5, 27 May 2013). http://apps.who.int/gb/ ebwha/pdf_files/WHA66/A66_R24-en.pdf.

51. Kumar VT: NFC in the Internet of Things (IOT) (Texas Instruments E2E Community Blogs: ConnecTIng Wirelessly, 17 September 2013). http://e2e.ti. com/blogs_/b/connecting_wirelessly/archive/2013/09/17/nfc-in-theinternet-of-things-iot.aspx.

52. GeoMobile and Internet of Things (OGC). http://www.opengeospatial.org/ projects/initiatives/geomobilecd.

53. Percivall G: Big Processing of Geospatial Data (August 2013). http://www. opengeospatial.org/blog/1866.

54. Percivall G: Smart Cities Depend on Smart Location (September 2013). http://www.opengeospatial.org/blog/1886.

55. Yu-Min Lin A: Can We See the Invisible, Together? (National Geographic NewsWatch - 14 January 2014). http://newswatch.nationalgeographic.com/ 2014/01/14/can-we-see-the-invisible-together/.

56. Walsh B: Google's Flu Project Shows the Failings of Big Data (TIME, 13 March 2014). http://time.com/23782/google-flu-trends-big-data-problems/.

57. Lazer D, Kennedy R, King G, Vespignani A, Lazer D1, Kennedy R, King G, Vespignani A: The parable of google flu: traps in big data analysis. Science 2014, 343(6176):1203-1205. doi:10.1126/science.1248506.

58. 'Internet of Things' to get $£ 45 \mathrm{~m}$ funding boost (BBC News, 9 March 2014). http://www.bbc.co.uk/news/business-26504696.

\section{Submit your next manuscript to BioMed Central and take full advantage of:}

- Convenient online submission

- Thorough peer review

- No space constraints or color figure charges

- Immediate publication on acceptance

- Inclusion in PubMed, CAS, Scopus and Google Scholar

- Research which is freely available for redistribution 